\title{
PENGELOLAAN SUMBER DAYA MANUSIA DALAM MENINGKATKAN PRODUKTIVITAS PADA KELURAHAN PANINGGILAN UTARA KECAMATAN CILEDUG
}

\author{
Desi Prasetiyani, Didi Sunardi, Karolina, Ratna Sari, Faisal \\ Universitas Pamulang \\ Email:dosen02452@unpam.ac.id
}

\begin{abstract}
UKM (Small and Medium Enterprises) is a very real economic activity in Indonesia. SMEs play an important role in the lives of Indonesian people, especially in the development and progress of the Indonesian economy. In addition, SMEs also play a role in employment, meaning SMEs also play a role in creating jobs. According to Presidential Decree No. 99 of 1998, the understanding of SMEs (Small and Medium Enterprises) is "Small-scale people's economic activities with business fields which are predominantly activities small businesses and need to be protected to prevent unfair business competition"(Irriyanti, 2012). Human Resources is an inseparable part of the relationship with an organization or company. An organization or company is certainly very unlikely to develop and progress without competent human resources in it. Along with the development of increasingly advanced times with rapid labor growth, human resources are required to have adequate expertise and abilities so that they are indeed eligible to be employed in an organization or company. The problems faced by the UKM UKM neighborhoods RW 013, Kelurahan Paninggilan Utara, Ciledug, Tangerang City are related to the productivity of UKM businesses and the management of Human Resources. Human resources, namely humans themselves as factors of production, like other factors of production, are inputs that are processed by the company and produce outputs. New employees who do not yet have the skills and expertise are trained, so that they become skilled and expert employees. that is mature so that it can support the business productivity of SME mothers. The method of activity used is in collaboration with the UKM UKM neighborhood RW 013, Paninggilan Sub-district, Ciledug Subdistrict, Tangerang City by analyzing the problems in the place so that it can provide the right solution in motivating members who are business owners of UKM UKM RW 013 , Kelurahan Paninggilan, Kecamatan Ciledug Kota Tangerang. After analysis, we provide training in the form of materials and practices aimed at developing the ability to improve productivity for members of UKM UKM neighborhood RW 013, Paninggilan Village, Ciledug District, Tangerang City.
\end{abstract}

Keywords: PKM, management of Human Resources in Increasing Productivity 
UKM (Usaha Kecil dan Menengah) merupakan kegiatan ekonomi yang sangat nyata yang ada diIndonesia. UKM sangat berperan penting terhadap kehidupan masyarakat Indonesia, khususnya terhadap perkembangan dan kemajuan perekonomian Indonesia. Selain itu, UKM juga berperan dalam penyerapan tenaga kerja, artinya UKM juga berperan menciptakan lapangan pekerjaan. Menurut Keppres RI No. 99 Tahun 1998 pengertian UKM (Usaha Kecil dan Menengah) adalah "Kegiatan ekonomi rakyat yang berskala kecil dengan bidang usaha yang secara mayoritas merupakan kegiatan usaha kecil dan perlu dilindungi untuk mencegah dari persaingan usaha yang tidak sehat" (Irriyanti, 2012).Sumber Daya Manusia merupakan bagian yang tidak bisa dilepaskan dari keterkaitan dengan suatu organisasi atau perusahaan. Suatu organisasi atau perusahaan tentu sangat tidak mungkin bisa berkembang dan maju tanpa adanya sumber daya manusia yang kompeten didalamnya. Seiring perkembangan zaman yang semakin maju dengan pertumbuhan tenaga kerja yang pesat, sumber daya manusia dituntut memiliki keahlian dan kemampuan yang memadai sehingga mereka memang layak untuk dipekerjakan dalam suatu organisasi atau perusahaan. Permasalahan yang dihadapi ibu-ibu UKM Lingkungan RW 013, Kelurahan Paninggilan Utara, Ciledug, Kota Tangerang berkaitan dengan produktivitas usaha UKM dan pengelolaaan sumber Daya Manusia. Sumber daya manusia yaitu manusia sendiri sebagai faktor produksi, seperti halnya faktor produksi yang lainnya, merupakan masukan (input) yang diolah oleh perusahaan dan menghasilkan keluaran (output). Karyawan baru yang belum memiliki keterampilan dan keahlian dilatih, sehingga menjadi karyawan yang terampil dan ahli. Apabila dia dilatih lebih lanjut serta diberikan pengalaman dan motivasi, dia akan menjadi karyawan yang matang sehingga dapat mendukung produktivitas usaha ibu-ibu UKM. Metode kegiatan yang digunakan adalah bekerjasama dengan ibu-ibu UKM Lingkungan RW 013,Kelurahan Paninggilan,Kecamatan Ciledug Kota Tangerang dengan memganalisis pemasalahan yang ada di tempat tersebut sehingga dapat memberikan solusi yang tepat dalam memotivasi anggota yang adalah pelaku bisnis ibu-ibu UKM Lingkungan RW 013,Kelurahan Paninggilan,Kecamatan Ciledug Kota Tangerang. Setelah di analisis maka kami memberikan pelatihan dalam bentuk materi dan praktek yang bertujuan mengembangkan kemampuan untuk meningkatkan produktivtas bagi para anggota ibu-ibu UKM Lingkungan RW 013, Kelurahan Paninggilan, Kecamatan Ciledug Kota Tangerang.

Kata Kunci: PKM, pengelolaaan sumber Daya Manusia Dalam Meningkatkan Produktivitas

\section{A. PENDAHULUAN}

UKM merupakan suatu bentuk usaha kecil masyarakat yang pendiriannya berdasarkan inisiatif seseorang. Sebagian besar masyarakat beranggapan bahwa UKM hanya menguntungka pihak-pihak tertentu saja.Padahal sebenarnya UKM sangat berperan dalam mengurangi tingkat pengangguran yang ada di Indonesia.UKM dapat menyerap banyak 
tenaga kerja Indonesia yang masih mengganggur.Selain itu UKM telah berkontribusi besar pada pendapatan daerah maupun pendapatan negara Indonesia.

Pelatihan dan pengembangan SDM yang tepat, dapat memberikan efek yang baik kepada ibu-ibu PKM Lingkungan RW 013, Kelurahan Paninggilan Utara, Ciledug. Ibu-ibu Lingkungan RW 013, Kelurahan Paninggilan Utara Ciledug. UKM dapat mengembangkan diri dan produktivitas serta mampu memahami seluk-beluk pelaksanaan lebih mendalam, dapat memahami perkembangan UKM memahami sasaran yang akan dicapai ibu-ibu UKM Lingkungan RW 013. Kelurahan Paninggilan Utara Ciledug, mengerti akan perlunya kerjasama dalam melaksanakan dengan ibu-ibu UKM Lingkungan RW 013, Kelurahan Paninggilan Utara, Ciledug, Kota Tangerang, dapat dengan mudah memahami Informasi yang disampaikan ibu-ibu UKM Lingkungan RW 013, Kelurahan Paninggilan Utara, Ciledug, Kota Tangerang, dapat memahami setiap kesulitan-kesulitan yang dihadapi ibu-ibu UKM Lingkungan RW 013, Kelurahan Paninggilan Utara, Ciledug, Kota Tangerang, mampu melakukan hubungan-hubungan dengan lingkungan, mampu memahami kebijaksanaan dan peratura yang berlaku dalam UKM, mampu memahami sistem dan prosedur yang digunakan dalam pelaksanaan tugas UKM, mampu memahami dan menerapkan perilaku yang mendukung UKM Lingkungan RW 013, Kelurahan Paninggilan Utara, Ciledug, Kota Tangerang.

UKM memiliki peranan sebagai penunjang bagi perekonomian secara mikro ketika usaha yang berskala besar cenderung memiliki kinerja yang kurang baik. UKM juga memanfatkan berbagai Sumber Daya Alam yang berpotensial di suatu daerah yang belum diolah secara komersial.UKM dapat membantu mengolah Sumber Daya Alam yang ada di setiap daerah.Hal ini berkontribusi besar terhadap pendapatan daerah maupun pendapatan negara Indonesia. Juga agar kita dapat mengetahui berapa besar keuntungan yang diperoleh apabila kita membuka sebuah usaha kecil dan menengah, dan kita dapat mengetahui cara mengelola usaha kecil dan menengah dengan baik, sehingga memperoleh laba yang cukup besar.untuk membangun sebuah usaha awal.

\section{B. METODE PELAKSANAAN KEGIATAN}

Metode kegiatan yang digunakan adalah bekerjasama dengan UKM Lingkungan RW 013,Kelurahan Paninggilan,Kecamatan Ciledug Kota Tangerang dan mencari pemasalahan yang ada di tempat tersebut sehingga dapat memberikan solusi yang tepat dalam memotivasi sebagai UKM di Lingkungan RW 013,Kelurahan Paninggilan,Kecamatan Ciledug Kota Tangerang. Setelah di analisis maka kami memberikan pelatihan dalam bentuk materi dan praktek dalam mengembangkan kemampuan pembuatan konten dalam pemasaran produk melalui media online kepada para anggota UKM Lingkungan RW 013 Kelurahan Paninggilan, Kecamatan Ciledug Kota Tangerang. Adapun jadwal pengabdian masyarakat yang sudah disepakati antara Tim PKM Universitas Pamulang dengan Karang Taruna Lingkungan RW 013,Kelurahan Paninggilan,Kecamatan Ciledug Kota Tangerang yaitu pada tanggal 5 Juni 2020 sampai dengan 7 Juni 2020 di UKM Lingkungan RW 013,Kelurahan Paninggilan,Kecamatan Ciledug Kota Tangerang.

\section{HASIL DAN PEMBAHASAN}

Kegiatan penyuluhan dan pelatihan dilaksanakan pada tanggal pada tanggal 5 Juni 2020 sampai dengan 7 Juni 2020 di UKM Lingkungan RW 013,Kelurahan Paninggilan,Kecamatan Ciledug Kota Tangerang tentang pengelolaan sumber daya manusia dalam meningkatkan produktivitas pada kelurahan paninggilan utara kecamatan ciledug dengan jumlah sebanyak 20 peserta. Kegiatan penyuluhan dan Pelatihan ini dimulai dengan melakukan Ice Breaking tujuannya untuk membuat suasana lebih akrab. Setelah itu, pemateri 
menayangkan slide power point yang berkaitan dengan materi dalam meningkatkan produktivitas SDM. Respon dari para ibu - ibu sangat baik. Terlihat ketika pemateri menanyakan hal apa saja yg bisa meningkatkan produktivitas salah satu ibu respon cepat menangkap pelajaran dari materi tersebut.

Dalam kegiatan tersebut ada beberapa perubahan yang dilihat dari ibu - ibu yang mengikuti kegiatan pelatihan dan pembinaan pengembangan pengelolaan sumber daya manusia dalam meningkatkan produktivitas karena ada beberapa guru yang sangat bersemangat dan termotivasi untuk meningkatkan keterampilan dalam proses pembelajaran. Mereka menyadari selama ini mereka kurang produktif dalam memanfaatkan waktu luang mereka untuk melakukan sesuatu yg bermanfaat.

Alhamdulillah kegiatan pelatihan dan pembinaan pengembangan kapasitas SDM dalam dunia Pendidikan berjalan cukup baik, karena semua ibu -ibu aktif dan merespon dengan baik dalam kegiatan ini. Berdasarkan wawancara, tanya jawab dan pengamatan langsung selama kegiatan berlangsung, kegiatan pengabdian pada masyarakat ini memberikan hasil sebagai berikut: Meningkatnya pengetahuan dan pemahaman para ibu - ibu tentang pengelolaan sumber daya manusia dalam meningkatkan produktivitas pada kelurahan paninggilan utara kecamatan ciledug.

\section{KESIMPULAN DAN SARAN}

\section{Kesimpulan}

Dalam meningkatkan profesionalitas para pelaku UMKM, memberikan pelatihan kewirusahaan dan pelatihan teknis untuk menambah keterampilan para pelaku UMKM di Kota Bandar Lampung. Untuk meningkatkan kemampuan manajerial bagi para pelaku UMKM, Lingkungan RW 013,Kelurahan Paninggilan,Kecamatan Ciledug Kota Tangerang melakukan penyuluhan terkait teknologi tepat guna, pelatihan manajemen keuangan dan manajemen produksi. Dalam mengembangkan jaringan bagi UMKM, memberikan penyuluhan tentang cara memperluas jaringan usaha dan pasar. juga menjalin kerjasama dengan BUMN yang ada di Kota Tangerang, BUMD, instansi lintas sektoral dan mengikutsertakan para pelaku UMKM dalam ajang promosi dan pameran baik pada tingkat lokal maupun nasional, selain itu upaya pengembangan jaringan juga dilakukan dengan pelaksanaan OVOP (one village one product). Upaya-upaya tersebut dimaksudkan agar pelaku UMKM memiliki daya saing untuk menghadapi MEA.

\section{Saran}

1. Untuk meningkatkan keprofesionalan bagi pelaku UMKM yang ada di Tangerang materi yang disampaikan harus lebih bervariasi bila perlu disertai dengan praktek langsung dan untuk memastikan penyampaian pelatihan diterima dengan baik, perlu melakukan evaluasi rutin.

2. Dalam meningkatkan akses pemasaran bagi UMKM di Tangerang sebaiknya menjalin kerjasama dengan pasar modern dan memanfaatkan media onlene dan memberikan ruang bagi UMKM untuk ikut memasarkan hasil produksinya.

\section{DAFTAR PUSTAKA}

Kurniawan. P. (2020), "Pengaruh Kecerdasan Intelektual Dan Kecerdasan Emosional Terhadap Kinerja Karyawan Pada PT. Bank Rakyat Indonesia (Persero) Cabang Tangerang Merdeka”. Jenius, Vol. 3. No. 3. 
Kurniawan, P. (2019), "Pengaruh Disiplin Kerja, Motivasi, Dan Komitmen Organisasi Terhadap Kinerja Karyawan Pada PT. Bank Rakyat Indonesia (Persero) Cabang Tangerang Merdeka", Jurnal Ekonomi Efektif, Vol. 1. No. 2.

Kurniawan, P. (2019), Pengaruh Motivasi dan Disiplin Kerja Terhadap Produktifitas Kerja Karyawan Pada PT. Daya Perkasa. Jurnal Mandiri. Vol. 2. No.2.

Solihin, D. (2020), Pengaruh Kepercayaan Pelanggan dan Promosi Terhadap Keputusan Pembelian Konsumen Pada Online Shop Mikaylaku Dengan Minat Beli Sebagai Variabel Intervening. JURNAL MANDIRI: Ilmu Pengetahuan, Seni, dan Teknologi, Vol. 4, No. 1.

Solihin, D. (2020), Faktor-Faktor yang Mempengaruhi Kinerja Pemasaran Pada PT. Prima Ufuk Semesta Studi Pada Outlet Rekanan PT. Prima Ufuk Semesta di Wilayah JABODETABEK, Jurnal Semarak, Vol. 3 No.1.

Solihin, D. (2020), Pengaruh Kualitas Pelayanan, Harga, Dan Promosi Terhadap Keputusan Pelanggan Dalam Memilih Klub Basket Satria Indonesia Tangerang Selatan, Jurnal Pemasaran Kompetitif, Vol. 3, No. 3.

Solihin, D. (2019), Pengaruh Current Ratio dan Debt to Equtity Ratio Terhadap Return on Asset (ROA) Pada PT. Kalbe Farma Tbk. Jurnal Kreatif, Vol. 7. No. 1. 